\title{
Prevalence and predictors of positive tuberculin skin test results in a research laboratory
}

\author{
Prevalência e fatores preditores do teste cutâneo de tuberculina \\ em um laboratório de pesquisa
}

Florian H. Pilsczek ${ }^{1,2}$ and Stefan H.E. Kaufmann ${ }^{1}$

\begin{abstract}
Latent tuberculosis was studied in a research laboratory. A prevalence of positive tuberculin skin test results ( $\geq 15 \mathrm{~mm}$ ) of $20 \%$ was found and the main predictors were place of birth in a foreign country with high prevalence of tuberculosis and a history of contact with patients with untreated active tuberculosis.
\end{abstract}

Key-words: Latent tuberculosis. Prevalence. Risk factors. Research laboratory.

\section{RESUMO}

A tuberculose latente foi estudada em um laboratório de investigação. Foi encontrada uma prevalência de $20 \%$ de resultados positivos para o teste cutâneo de tuberculina ( $\geq 15 \mathrm{~mm}$ ) e os principais fatores preditores foram ser natural de um país estrangeiro com alta prevalência de tuberculose e ter uma história de contato com doentes com tuberculose ativa não tratada.

Palavras-chaves: Tuberculose Latente. Prevalência. Fatores de risco. Laboratório de pesquisa.

Latent tuberculosis after infection with Mycobacterium tuberculosis with no evidence of disease affects up to one third of the world population ${ }^{518}$. The frequency of a positive tuberculin skin test (TST) reaction as a diagnostic test for latent tuberculosis ${ }^{1314}$ in the general population in Asia is: India 41\% ${ }^{12} 14$, Pakistan 40\%, South Korea 87\%, Cambodia 39\% and Afghanistan 34\%; in Africa: South Africa 38\% and Zimbabwe $64 \%{ }^{5}$, in Europe: the Netherlands $4 \%{ }^{1}$, Germany $29 \%{ }^{4}$, Italy $40 \%{ }^{16}$ and United Kingdom $27 \%{ }^{17}$, and in America: the Pacific Region 15\%, Canada 17\% and USA 22\%. We studied the frequency of positive TST results among laboratory members and epidemiological risk factors for positive tuberculin skin test results to identify subjects with a high likelihood of latent tuberculosis.

Study subjects. We evaluated 65 out of 100 laboratory members (scientists and technicians) who provided informed consent for their participation. No formal sample size calculation was performed. The exclusion criteria were medical illness (e.g. diabetes) or taking immunosuppressive drugs (e.g. corticosteroids).

Setting. The setting was an inner-city biomedical research laboratory in Berlin with a biosafety level 3 facility that included research with Mycobacterium tuberculosis.
Data collection. During the study period between 2005 and 2007, standardized clinical and epidemiological data were collected by one of the authors (FHP) during an interview, followed by the tuberculin skin test.

Tuberculin skin testing. Quantitative tuberculin skin testing was performed by FHP by means of intracutaneous injection of 5TU of PPD (purified protein derivative) in $0.1 \mathrm{ml}$ of solution (Tubersol, Pasteur Aventis, Canada) into the volar aspect of the forearm (Mantoux test). Induration was read after 48 to 72 hours and recorded in $\mathrm{mm}$ by one trained examiner (FHP).

Study approval. All probands provided informed consent and the study was approved by the institutional review board.

In total, 65 probands were studied (mean age 33 years and range 23 - 57 years); 34 (52\%) were male and 31 (48\%) were female (Table 1). Thirteen (20\%) probands had a TST result $\geq 15 \mathrm{~mm}$, two $(3 \%) \geq 10 \mathrm{~mm}, 17(26 \%) \geq 5 \mathrm{~mm}$ and $33(51 \%)$ less than $5 \mathrm{~mm}$. According to clinical risk factors, 13 (20\%) probands had a positive tuberculin skin reaction and 52 (80\%) had a negative reaction ${ }^{17}$.

Fifty-four (83\%) robands had a history of BCG (Bacille Calmette-Guérin) vaccination, eight (12\%) had not had the

\footnotetext{
1. Max-Planck-Institute for Infection Biology, Department of Immunology, Berlin, Germany. 2. Immunology Research Group, Department of Physiology and Biophysics, University of Calgary, Calgary, Alberta, Canada.

Address to: Dr. Florian Pilsczek. Immunology Research Group/Department of Physiology and Biophysics/University of Calgary, Calgary T2N 4N1, Alberta, Canada. Tel: 403-220-7658, Fax: 403-270-7516

e-mail: f.h.pilsczek@gmail.com

Recebido para publicação em 23/10/2007

Aceito em 02/07/2008
} 
Table 1 - Tuberculin skin test (TST) results and clinical and epidemiological data on study probands.

\begin{tabular}{llll}
\hline Variable & Results & Number & Percentage \\
\hline Age (years) mean (range) & & $33(23-57)$ & \\
\hline Sex & male & 34 & 52.0 \\
& female & 31 & 48.0 \\
\hline TST result (mm) & $<5$ & 33 & 51.0 \\
& $\geq 5$ & 17 & 26.0 \\
& $\geq 10$ & 2 & 3.0 \\
& $\geq 15$ & 13 & 20.0 \\
\hline Interpretation & positive & 13 & 20.0 \\
\hline BCG vaccination & negative & 52 & 80.0 \\
& yes & 54 & 83.0 \\
\hline Contact with active untreated & no & 8 & 12.0 \\
tuberculosis & unknown & 3 & 5.0 \\
\hline Travel history & & 8 & 12.0 \\
\hline Native-born & & 22 & 34.0 \\
\hline Foreign-born & & 52 & 80.0 \\
\hline Mycobacteriology work & yes & 35 & 20.0 \\
\hline
\end{tabular}

TST result interpretation: according to result and clinical risk factors; ${ }^{14}$ contact with patients with untreated active tuberculosis: history of contact (e.g. in workplace, school or home); positive travel history: visit to a country with high prevalence of tuberculosis (e.g. working as a health professional in Africa or living in India); foreign-born: (one in Russia, one in China, ten in India and one in United Kingdom). BCG: Bacille Calmette-Guérin, TST: tuberculin skin test.

BCG vaccination and three (6\%) did not know. Eight (12\%) probands had a history of contact with patients with untreated active tuberculosis (e.g. in workplace, school or home). Twentytwo (34\%) probands had a positive history of travel to a country with high prevalence of tuberculosis (e.g. working as a health professional in Africa or living in India for at least one year). Fifty-two (80\%) probands were native-born (in Germany) and 13 (20\%) were foreign-born (one in Russia, one in China, ten in India and one in the United Kingdom). Thirty-five (54\%) probands had a history of working in a mycobacteriology laboratory with exposure to Mycobacterium tuberculosis. The thirteen (20\%) laboratory members with a TST reaction $\geq 15 \mathrm{~mm}$ (Table 2) had a mean age of 34 years (range 24 - 49 years); five (38\%) were male and eight (62\%) were female. Twelve (92\%) of them had a history of BCG vaccination. Three (23\%) of them had a history of contact with patients with untreated active tuberculosis; ten (23\%) had a positive travel history (see above); eight (62\%) were foreign-born (see above); and nine (69\%) had worked in a mycobacteriology laboratory with exposure to Mycobacterium tuberculosis.

The risk factors associated with a positive tuberculin skin reaction were therefore: place of birth in a foreign country; contact with patients with untreated active tuberculosis; positive history of travel to a country with high prevalence of tuberculosis; and history of working in a mycobacteriology laboratory. Based on the subjects' positive tuberculin skin reactions, a risk factor for infection with Mycobacterium tuberculosis other than a history of working in a mycobacteriology laboratory could be identified for all probands.
Table 2 - Frequency of positive tuberculin skin tests (TST) $(\geq 15 \mathrm{~mm})$ and clinical and epidemiological data. Explanation of terms: see Table 1

\begin{tabular}{llll}
\hline Variable & Results & Number & Percentage \\
\hline Age (years) mean(range) & & $34(24-49)$ & \\
\hline Sex & male & 5 & 38 \\
& female & 8 & 62 \\
\hline TST result (mm) & $\geq 15$ & 13 & 20 \\
\hline BCG vaccination & yes & 12 & 92 \\
& no & 0 & 0 \\
\hline Contact with & unknown & 1 & 8 \\
untreated active & & 3 & 23 \\
tuberculosis & & & \\
\hline Travel history & & 10 & 23 \\
\hline Native-born & & 5 & 38 \\
\hline Foreign-born & yes & 9 & 69 \\
\hline MycobacteriologyWork & no & 4 & 31 \\
\hline
\end{tabular}

BCG: Bacille Calmette-Guérin, TST: tuberculin skin test

On average, the worldwide frequency of positive tuberculin skin test reactions is $30 \%$, and it can be as high as $80 \%$ in particular risk groups such as those that are in contact with patients with untreated active tuberculosis, or less than $20 \%$ in low-endemicity areas such as Canada or the Netherlands ${ }^{5} 918$. The total frequency of positive tuberculin skin reactions in this laboratory was $20 \%$, and this is comparable with previous studies on positive tuberculin skin reactions in Germany and lower than the average of $30 \%$ worldwide (Table 1$)^{451011}$

The most important associated factors for infection with Mycobacterium tuberculosis and for a positive TST reaction in this study were: place of birth in a foreign country with high prevalence of tuberculosis such as India and contact with patients with untreated active tuberculosis. Most probands were TST-positive if they were foreign-born in a country with high prevalence of tuberculosis or had histories of contact with patients with untreated active tuberculosis (Table 2). Thus, either of these criteria makes it possible to identify individuals who are likely to be TST-positive (i.e. PPD-positive), e.g. for the purpose of finding probands for research on latent tuberculosis using peripheral blood samples.

Another known risk factor for infection with Mycobacterium tuberculosis is to work in a laboratory with live Mycobacterium tuberculosis, e.g. with clinical samples from patients for diagnostic testing $^{237815}$. However, there have been few reports of airborne acquired active infection with Mycobacterium tuberculosis consequent to diagnostic mycobacteriology laboratory work over the last ten years in North America and Europe. The risk of infection in a biosafety level 3 facility is similar to the risk among the general population if standard precautions are followed ${ }^{314}$. Grist et $\mathrm{al}^{7}$ studied evidence of tuberculosis acquired during work activities in more than 200 laboratories in the United Kingdom and only identified one case, in a mortuary technician ${ }^{7}$. Nonetheless, infection remains a possible complication of working with live Mycobacterium tuberculosis. Employees involved in the disposal of medical waste have been found to have an increased risk of infection with Mycobacterium tuberculosi ${ }^{15}$. 
Before the general use of safety cabinets and face masks for handling Mycobacterium tuberculosis specimens became standard practice in industrialized countries over ten years ago, the risk among laboratory personnel of acquiring tuberculosis was markedly higher and was estimated to be between 100 and 200 times greater than among the general public ${ }^{615}$.

For the purpose of identifying latently infected individuals in the laboratory, two associated factors (place of birth in a foreign country with a high prevalence of tuberculosis and history of exposure to patients with untreated active tuberculosis) are useful preselection criteria before performing tuberculin skin testing.

\section{REFERENCES}

1. Cobelens FG, van Deutekom H, Draayer-Jansen IW, Schepp-Beelen AC, van Gerven PJ, van Kessel RP, Mensen ME. Association of tuberculin sensitivity in Dutch adults with history of travel to areas of with a high incidence of tuberculosis. Clinical Infectious Diseases 33: 300-304, 2001

2. Collins CH. Laboratory-acquired tuberculosis. Tubercle 63: 151-155, 1982

3. Collins CH, Grange JM. Tuberculosis acquired in laboratories and necropsy rooms. Community Diseases Public Health 2: 161-167, 1999.

4. Daniello J, Zollner I. Experiences with the intracutaneous Mendel-Mantoux tuberculin test in routine screening in a public health office. Gesundheitswesen 59: 519-522, 1997.

5. Dye C, Scheele S, Dolin P, Pathania V, Raviglione MC. Consensus statement. Global burden of tuberculosis: estimated incidence, prevalence, and mortality by country. WHO Global Surveillance and Monitoring Project. Journal of the American Medical Association 282: 677-686, 1999.

6. Grist NR, Emslie J. Infections in British clinical laboratories, 1982-3. Journal of Clinical Pathology 38: 721-725, 1985.

7. Grist NR, Emslie JA. Infections in British clinical laboratories, 1986-87. Journal of Clinical Pathology 42: 677-681, 1989.

8. Kao AS, Ashford DA, McNeil MM, Warren NG, Good RC. Descriptive profile of tuberculin skin testing programs and laboratory-acquired tuberculosis infections in public health laboratories. Journal of Clinical Microbiology 35: 1847-1851, 1997.

9. Lalvani A, Nagvenkar P, Udwadia Z, Pathan AA, Wilkinson KA, Shastri JS, Ewer K, Hill AV, Mehta A, Rodrigues C. Enumeration of T cells specific for RD1-encoded antigens suggests a high prevalence of latent Mycobacterium tuberculosis infection in healthy urban Indians. Journal of Infectious Diseases 183: 469-477, 2001

10. Maciel EL, Meireles W, Silva AP, Fiorotti K, Dietze R. Nosocomial Mycobacterium tuberculosis transmission among healthcare students in a high incidence region, in Vitória, State of Espírito Santo. Revista da Sociedade Brasileira de Medicina Tropical 40: 397-399, 2007.

11. Maciel EL, Viana MC, Zeitoune RC, Ferreira I, Fregona G, Dietze R. Prevalence and incidence of Mycobacterium tuberculosis infection in nursing students in Vitória, Espírito Santo. Revista da Sociedade Brasileira de Medicina Tropical 38: 469-472, 2005

12. Pai M, Gokhale K, Joshi R, Dogra S, Kalantri S, Mendiratta DK, Narang P, Daley CL, Granich RM, Mazurek GH, Reingold AL, Riley LW, Colford JM. Mycobacterium tuberculosis infection in health care workers in rural India: comparison of a whole-blood interferon gamma assay with tuberculin skin testing. Journal of the American Medical Association 293: 2746-2755, 2005.

13. Pai M, Kalantri S, Dheda K. New tools and emerging technologies for the diagnosis of tuberculosis: part I. Latent tuberculosis. Expert Reviews of Molecular Diagnosis 6: 413-422, 2006.

14. Peerbooms PG, van Doornum GJ, van Deutekom H, Coutinho RA, van Soolingen D. Laboratory-acquired tuberculosis. Lancet 345: 1311-1312, 1995

15. Roncarati E, De Bartolomeo A, Atti G. Tuberculin survey and its meaning for a correct prevention in a high risk population. Epidemiological data relative to students of the faculty of medicine and soldiers residing in Ferrara (author's transl). Annals Sclavocia 22: 982-992, 1980.

16. Syed Q, Bellis MA, Beeching NJ, Tocque K, Williams CS, Jamieson J, Steele A, Davies PD. Tuberculin testing in two Liverpool social clubs: the effects of a tuberculosis outbreak on background positivity. Thorax 51: 624-627, 1996.

17. Targeted tuberculin testing and treatment of latent tuberculosis infection. American Journal of Respiratory and Critical Care Medicine 161: S221-S247, 2000 .

18. Tufariello JM, Chan J, Flynn JL. Latent tuberculosis: mechanisms of host and bacillus that contribute to persistent infection. Lancet Infectious Diseases 3: 578-590, 2003. 